\title{
INTEGRATING CONFLICT: A PROPOSED FRAMEWORK FOR THE INTERDISCIPLINARY STUDY OF WORKPLACE CONFLICT AND ITS MANAGEMENT
}

\author{
Ariel C. Avgar \\ Cornell University \\ Paper Submitted to the Special ILRR Conflict Management Conference
}

Honoring David B. Lipsky

October 1, 2017 


\section{Introduction: Fragmentation and Silos in the Study of Conflict and Its Management}

Conflict and its management are perennial dimensions of organizational life--ever present with significant consequences for a host of employer and employee related outcomes. All organizations, regardless of industry, union status, workforce characteristics, managerial strategy, organizational culture, or performance levels are confronted with the need to address, deal with or manage the myriad manifestations of workplace conflict. As such, all organizations manage conflict in one way or another, whether they adopt a proactive stance or whether they are avoidant and reactive.

Recognized as a central workplace feature, scholars from a variety of different disciplines, including, but not limited to, industrial relations, organizational behavior, and law, have devoted a great deal of conceptual and empirical attention to the study of conflict and conflict management. Much of this, scholarship, however, has been conducted in isolation with limited cross-disciplinary engagement. The central argument set forth in this paper is that conflict scholarship has paid a hefty price for the disciplinary silos that have emerged across these domains. Each of these disciplines has provided a wealth of conflict related findings and insights that have advanced existing knowledge. At the same time, these insights have, for the most part, been incomplete due to the absence of integration across longstanding, well defined, and mostly impenetrable disciplinary boundaries. As a result, the scholarly and practical utility of the body of knowledge that has been amassed across these different disciplines has been, at times, limited.

There is, therefore, a great deal to be gained by building disciplinary bridges to better integrate insights that tackle fundamentally different dimensions of central conflict and conflict management phenomena at different levels of analysis, applying different underlying assumptions, and using different methodological tools and approaches. The existing disciplinary 
boundaries have stifled scholars' ability to paint a nuanced and complete portrait of what we already know across these different domains and to shed new light on what we do not yet know. Conflict and the varied organizational efforts to manage it, do not heed to the constructed and self-imposed disciplinary boundaries and reside across different levels of analysis, involve different stakeholders, and influence a host of outcome categories, regardless of whether they are captured and analyzed by a given discipline.

Thus for example, industrial relations scholars have placed conflict at the heart of the discipline's traditional and emerging focus. Early industrial relations scholarship documented the fundamental role that conflict plays within the labor management relationship. In addition to highlighting the inherent conflicts between industrial relations actors, these scholars also captured labor relations efforts to institutionalize the resolution of conflict through collective bargaining and the grievance systems that they gave rise to. More recently, this discipline has applied an industrial relations lens to the development of dispute resolution practices in the nonunion setting. Organizational behavior scholars, for their part, have made conflict central to their discipline's efforts to better understand relational dynamics. Much of this research has examined the performance related consequences associated with different types of team level conflict. Alongside research on team level conflict and its consequences for performance and other outcomes, organizational behavior scholars have also attempted to better understand the ways in which individuals and teams manage conflict, distinguishing between a number of different styles and strategies and linking these to performance outcomes. Finally, legal scholarship has also shown a great deal of interest in organizational efforts to manage conflict. This body of research has focused on specific dispute resolution practices, such as arbitration and mediation, in an effort to compare these, procedurally and substantively, to the resolution of disputes using 
the traditional court system. As such, legal scholars have engaged in a series of debates regarding the procedural and substantive adequacy of private organizationally-centered dispute resolution practices. While the organizational behavior research focuses on individual and team levels of analysis and the industrial relations scholarship tends to focus on the organizational level of analysis, legal scholars incorporate societal level considerations and outcomes of interest.

Each of these disciplines has contributed a great deal of important theoretical and empirical evidence to the study of workplace conflict, but we have yet to fully leverage these disparate contributions in an overarching, integrated, and coherent manner. How are outcomes at the group level influenced by organizational level efforts? To what extent do conflict and conflict management dynamics at the team and individual levels shape broader organizational strategies? What is the relationship between external legal pressures and conflict patterns and trends across levels of analysis within organizations? These are but a few of the questions that cannot be fully answered given the current state of research across disciplines.

The absence of a coherent interdisciplinary integration of conflict research rests, to a large extent, on the fact that each discipline has focused on qualitatively different dimensions of conflict and its management with an emphasis on different actors operating at different levels of analysis, and with a focus on a different set of outcomes. A comprehensive understanding of organizational conflict requires, therefore, a framework that can assist in piecing together the rich tapestry of conflict and conflict management insights developed over the past decades across different substantive domains, involving different actors, and playing out at different levels of analysis. This paper seeks to contribute to existing conflict and conflict management research by proposing a theoretical framework capable of containing and integrating findings and insights 
amassed across these disciplinary boundaries, and, in doing so, developing new theoretical linkages and highlighting new avenues for research.

Specifically, I maintain that the three tiered industrial relations framework proposed by Kochan, Katz, and McKersie in the 1980s and reviewed in detail below, is uniquely suited to situate and organize what we know about conflict and its management and to highlight areas that have been neglected as a result of overly rigid disciplinary divides (Kochan et al., 1986; also see Kochan, McKersie, and Cappelli, 1984). This framework, which was developed as part of a broader effort to understand dramatic changes occurring within and across American organizations in the 1970s and 1980s, identifies three key levels of industrial relations activitythe strategic level, the function level, and the workplace level. Central to Kochan and colleagues' argument is the proposition that dynamics within each of these levels of activity are inextricably linked to one another. Furthermore, activities across these levels are influenced by a host of environmental pressures that shape the strategic choices made by various key actors, and that these choices, in turn, help to explain a host of organizational and individual level outcomes. As will be proposed below, this explicit recognition of the interrelated nature of dynamics that occur across these level of analysis alongside the acknowledgement of the antecedents to and consequences of actors' strategic choices, provide a useful and fitting foundation on which to begin the necessary task of piecing together conflict scholarship insights.

In what follows, I will review key themes, findings, and insights advanced by organizational behavior, industrial relations, and legal scholars. Building on this review, I will identify the barriers associated with existing disciplinary boundaries and the costs that these have had in terms of our current understanding of conflict and its management in organizations. This review will also point to the many potential areas of integration and their likely benefit to existing 
scholarship. Next, I will introduce the three tiered framework and its potential to serve as a means of bridging disciplinary silos. Finally, I will propose a series of theoretical linkages that stem from the integration of conflict insights across disciplines, which serve as the basis for an integrated future research agenda.

\section{Individual and Team Level Conflict Research: An Organizational Behavior Lens}

As noted above, much of what is known about how conflict affects teams and individuals is the product of decades of accumulated research conducted by organizational behavior scholars (for a recent review see Avgar and Colvin, 2016; for an additional review see Wall and Callister, 1995). Taken together, this body of research paints a fine grained portrait of the manner in which conflict plays out at the team and individual levels by, among other things, distinguishing between different types of conflict and linking each of these to various performance measures. As such, this research has provided a great deal of evidence regarding the micro and meso consequences associated with different forms of conflict. Consistent with this paper's overarching argument, this evidence has, for the most part, not been leveraged to inform industrial relations or legal scholarship even though each of these disciplines stands to benefit from a more explicit recognition and understanding of how conflict influences workplace level dynamics and outcomes. As will be proposed below, there are a number of clear linkages between this organizational behavior-centered research and the types of questions being explored by industrial relations and legal scholars. In order to address this disciplinary blind spot, I will review a number of key insights and outline the manner in which these could inform other conflict research streams. For a summary of disciplinary insights see Table 1.

--Insert Table 1 about Here-- 
First, the organizational behavior literature on conflict has sought to identify and distinguish different types of workplace conflict (see for example, Amason, 1996; De Dreu, 1997; Jehn, 1997). The central argument guiding the development of a conflict typology is that not all forms of conflict are cut from the same cloth. Conflicts vary both in terms of their substantive underpinnings and their consequences for individuals and teams, and organizations by extension. General propositions about the effects of conflict that do not account for their substantive nature are likely, according to this argument, to gloss over distinct conflict attributes. Although a number of typologies have been developed, one of the most established and well cited typology distinguishes between task, relationship, and process related conflicts (Jehn, 1995, 1997). Task conflict as a conceptual construct captures tensions and disagreements that center around the work being done in the group or team. Teams engaged in task conflict grapple with different opinions and approaches to executing assigned tasks and responsibilities. Relationship conflict, on the other hand, centers on interpersonal tensions and disagreements that are not directly related to the work being done by the group or team. This form of conflict relates to how well team members get along as opposed to how much consensus they achieve about the ways in which to perform work related tasks. Finally, process conflict represents the tensions and disagreements that arise in teams about the procedural and administrative aspects of the work being conducted as opposed to the content or substantive nature of these responsibilities (Jehn and Mannix, 2001). Process conflict is related, therefore, to the manner in which teams organize their work responsibilities as opposed to how they execute them.

The typology set forth by organizational behavior scholars contributes to a more nuanced understanding of team level conflict. Furthermore, this conceptualization of different types of conflict provides a theoretical and empirical foundation for the examination of the functional and 
dysfunctional nature of conflict. In distinguishing between different types of conflict, this research has set the stage for an analysis of the costs and benefits associated with each type of conflict. Thus, a second category of insights produced by this body of research relates to the performance outcomes associated with different types of conflicts. At the heart of this stream of research is an effort to challenge the traditional and often prevalent assumption that all forms of conflict carry with them primarily negative consequences for teams and their members. Could conflict actually have benefits that enhance certain key performance outcomes? The answer to this question according to a large number of organizational behavior scholars is yes. In the 1990s, organizational scholars began exploring the possibility that alongside its costs, some types of conflict could serve as a means of improving team functioning and performance (De Dreu, 1997; Jehn 1995, 1997).

In particular, this research found a significant and positive relationship between task conflict and team performance. Thus for example, in her seminal 1995 study of 105 work groups and management teams, Karen Jehn found that in teams that performed non-routine tasks, certain levels of task conflict were associated with improved performance (Jehn 1995). Task conflict, according to this stream of research, promotes healthy disagreements and debates about how work is conducted and in so doing pushes team members to rethink and reconsider traditional ways of doing things. As a result, teams that experience task conflict may benefit from the challenging of ineffective and inefficient ways of performing tasks (De Dreu, 1997; Jehn 1995, 1997; De Dreu, 2006; Farh, Lee \& Farh, 2010). Process conflict has also been shown, under certain conditions and if experienced during specific team lifecycle stages to have a positive effect on performance (Jehn and Manix 2001). Relationship conflict, on the other, has been consistently shown to negatively affect team level outcomes. 
It is also important to note that this literature has led to a longstanding and ongoing debate about the extent to which certain types of conflict are beneficial to team and individual level outcomes. A number of studies, including meta-analyses, have provided a much more qualified portrait of the potential benefits associated with task and process conflict (see for example De Dreu and Weingart, 2003; de Wit et al., 2012). Thus for example in their frequently cited 2003 meta-analysis, De Dreu and Weingart found that both task and relationship conflict have a negative effect on team performance (De Dreu and Weingart, 2003; for a more recent meta analysis see De Wit et al., 2012). In this article, I do not take a stand as to the potential benefits that task and process conflict may have in terms of team performance. Rather, I wish to highlight the debate's contribution to shifting the manner in which organizational behavior scholars conceptualize and study conflict. This debate has forced scholars to contend with the wide array of potential effects that conflict can have on teams. As such, this research offers a treasure trove of evidence regarding the inner workings of conflict at the team level. These insights are likely to lend themselves to interdisciplinary linkages that will be highlighted below.

Interestingly, much of the evidence regarding the positive effects of task and process conflict focus on team level outcomes, such as productivity or innovation (Amason, 1996; Amason and Sapienza, 1997; Jehn, 1995; Jehn, Northcraft, \& Neale, 1999). There is, however, considerable consensus across this discipline that all types of conflict have mostly negative consequences for individual level outcomes, such as job satisfaction, stress, and employee wellbeing (see for example Avgar et al., 2014). In fact, one of the critiques of this body of research is its relative disregard for employee related outcomes (for a similar discussion see Avgar et al., 2014). As will be discussed below, this serves as another area of interdisciplinary exchange. In particular, industrial relations scholarship pays a great deal of attention to employee level outcomes and 
can, therefore, leverage this focus to complement the existing organizational behavior research on the effects of conflict on individual team members and employees.

Another area that has not received a great deal of attention within the organizational behavior literature is the antecedents to conflict. Most of the attention in this area of research is given to the role that conflict plays as an explanatory variable predicting certain group level performance outcomes. Conflict is rarely analyzed as an outcome variable being influenced by a set of factors. As such, we know very little about how organizational, team, and individual level factors give rise to, shape, or hinder the manifestation of different forms of conflict. Do different organizational practices and arrangements affect the level of conflict experienced within teams? This is another natural area of overlap with industrial relations research, which has paid careful attention to a host of factors such as workplace systems, practices and process that are likely to affect workplace conflict, (for a similar argument see Lee, Hong, and Avgar, 2015).

A third insight associated with this body of research stems from efforts made by scholars to address inconsistent and contradictory findings about the performance consequences of conflict. In addressing the question of costs and benefits associated with different types of conflict, recent scholarship has begun to pay more careful attention to the context in which conflict arises (see for example Avgar et al., 2014). More specifically, this stream of research has explored the extent to which organizational, team, and individual level factors moderate the relationship between different types of conflict and performance outcomes (for a conceptual discussion of the effects that context might have on organizational conflict see Jehn and Bendesky, 2003). These studies have documented the contingent effects that conflict has on outcomes as a function of the context in which it arises. This contingency perspective, which has tended to have a relatively narrow scope in terms of the type of contextual factors considered, is an especially fruitful area 
of inquiry in terms of potential interdisciplinary linkages. Growing emphasis on the organizational context, provides for another natural area of overlap with industrial relations scholarship, which is acutely attuned to a broader array of contextual factors. As such, the emerging organizational behavior interest and evidence regarding context provides an opportunity of interdisciplinary research efforts.

Finally, alongside their interest in the nature and consequences associated with conflict, organizational behavior scholars have also explored the ways in which individuals and teams manage and deal with conflict. This stream of research has been influential in distinguishing between a number of overarching conflict management styles. Beginning in the 1960s, organizational behavior scholars have sought to categorize the different approaches adopted by individuals and teams when they are confronted with conflict (Blake and Mouton, 1970). One of the most influential frameworks in this area of research has been the dual concern model. According to this framework, first developed by Blake and Mouton (1970) and then extended by Thomas (1976), an individual's response to conflict is, at its core, a function of two types of concerns - a concern for one's own outcomes or results and a concern for other's outcomes or results. Plotting these concerns in a two-by-two matrix, five overarching conflict management styles emerge. Individuals and teams that have a high level of concern for their own outcome by are low on their concern for others’ outcomes, are likely to adopt a competitive conflict management style. Those that are high in terms of their concern for others and low on their emphasis on their own outcomes are likely to adopt a yielding conflict management style. Individuals and teams that are characterized by a low level of concern for both categories of outcomes are likely, according to this framework, to adopt an avoidance approach to conflict. Compromise, a fourth conflict management style, is the product of a moderate level of concern 
for both outcomes. Finally, individuals and teams that are high on their levels of concern for both types of outcomes are likely to utilize a problem solving conflict management approach.

This conceptual framework has been extended by a relatively large body of research seeking to operationalize and measure each of these styles (see for example Rahim, 2002, 1983). While this body of research has had a broad scholarly and practitioner reach, this reach has, for the most part, not extended outside the organizational behavior discipline. Like the existing research on conflict and its consequences, conflict management styles have not been leveraged in an effort to better understand other conflict related phenomena. As with the organizational behavior research on conflict, a number of questions have yet to be explored. The conflict management styles research focuses on the role that individual and group preferences and priorities play in explaining responses to conflict. Nevertheless, it is likely that other factors, organizational and environmental, are likely to also shape individual and group responses to conflict. Integrating such factors will, consistent with the overarching argument set forth in this paper, require an expansion of the disciplinary lens applied to this area of research.

\section{Conflict Management at the Organizational Level: An Industrial Relations Lens}

Like the organizational behavior scholarship reviewed above, industrial relations research has contributed greatly to the existing conflict and conflict management body of knowledge (for a recent review see Roche et al., 2014). Nevertheless, the focus of this research is vastly different. While the organizational behavior research centers around team member attitudes and perceptions and their consequences at the individual and groups levels, industrial relations scholars have long been interested in the institutional arrangements designed to contain and manage conflict. As such, the industrial relations lens provides a view of the organizational level features associated with conflict and its management in union and nonunion settings (see 
Godard, 2014). This is not to say that industrial scholars do not address individual level factors. This research has examined employee attitudes, perceptions, and behaviors, such as job satisfaction, commitment, and turnover. Nevertheless, these individual level variables are studied in the context of broader organizational systems, practices, and process and are linked to broader organizational performance measures.

As noted above, conflict stands at the heart of the industrial relations paradigm (Godard, 2014; Lewin, 2001; Godard and Delaney, 2000; Barbash, 1984; Fox, 1974; Commons, 1935; Web and Web, 1897). In fact, this discipline is founded on the paradigmatic premise that the relationship between labor and management is infused with inherent and inextricable conflict due, in large part, to the existence of an unavoidable competition of interests between the parties. While this conflict cannot be eradicated, industrial relations research has highlighted the role that institutional arrangements and practices can play in containing and diffusing it. Traditional industrial relations research has, therefore, focused on the conflict inherent to the labormanagement relationship (Godard, 2014), on the formal negotiations between the parties (Walton and McKersie, 1965), and on the grievance system and its effects on turnover, employee perceptions, and organizational performance (Avgar and Colvin, 2016; Lewin, 2014; Katz et al., 1983).

Much of this discipline's attention has been directed towards the development of a nuanced understanding of the structures, practices, and processes implemented by organizations and the unions representing their employees in an effort to resolve disputes and manage conflict. Given the traditional disciplinary emphasis on the unionized labor-management relationship, much of this research has examined the unionized grievance system's ability to address disputes that arise under the collective bargaining agreement and the consequences for organizational and 
individual outcomes. The unionized grievance system represents a central vehicle through which labor and management are capable of channeling unavoidable disputes, thereby creating conditions in which conflict is not as detrimental as it could otherwise be (Lewin, 2014).

More recently and as will be discussed below, industrial relations scholars have leveraged the knowledge and expertise attained over decades of research in the union setting in an effort to document organizational conflict management patterns and trends in the nonunion setting (for a review, see Lipsky, Avgar, and Lamare, 2014 and Colvin et al., 2006; also see Colvin, 2003). Given its disciplinary prominence, it is virtually impossible to do justice to a broad range of conflict and conflict management insights generated within industrial relations scholarship. For the purposes of the argument set forth in this paper, I will review two key areas of research that highlight the potential for integration with other disciplines - the unionized grievance system and the link between conflict in this setting and organizational performance, and the emerging research on organizational conflict management in the nonunion setting.

First, as noted above, the grievance system stands at the heart of the labor-management relationship and plays a central role in addressing conflicts and disputes that arise out of disagreements over the interpretation or implementation of the jointly negotiated collective bargaining agreement (Colvin and Avgar, 2017). In the United States, the grievance system and its inclusion of a final and binding arbitration step received substantial support from the Supreme Court in 1960 and continues to be one of the centerpieces of the collective bargaining relationship since (Lewin, 2014). Interestingly, the grievance system has remained extremely stable with a number of relatively similar steps that lead up to a formal and binding arbitration procedure (Colvin and Avgar, 2017). Nevertheless, some experimentation has taken place over 
the years with efforts to introduce different practices designed to resolve contractual disputes, such as mediation (see for example Brett and Goldberg, 1983).

Industrial relations scholars have examined a number of grievance system dimensions. Among these, researchers have been interested in both the factors that explain individual grievance filings and the consequences associated with this grievance activity. With regards to grievance filings, scholars have focused on environmental, organizational, and individual level factors that help to explain why union members make use of the grievance system procedures (see for example Bemmeles and Foley, 1996; Lewin and Peterson, 1988). In contrast to the organizational behavior research that provides little evidence regarding the antecedents to conflict, these studies have identified a host of factors that predict grievance activity, which can be seen as a formal manifestation of conflict. On the other hand, while the organizational behavior research has offered a nuanced depiction of conflict by distinguishing between different types, this industrial relations research has paid very little attention to the likely differences across types of grievances. This limitation is, in part, due to the fact that industrial relations research has focused primarily on the formal expression of workplace conflict captured by grievances. Taken together, the industrial relations attention to grievance filing antecedents can serve as a foundation upon which to extend the organizational behavior research on conflict and its consequences. At the same time, industrial relations research could benefit from a more careful analysis of different types of grievances, which would allow for a more detailed analysis of the consequences associated with different grievance categories.

With regards to the consequences associated with grievance activity, industrial relations research has contributed greatly to an understanding of how the institutionalization of voice influences individual employee behavior. Most notably, this research, pioneered by Freeman and 
Medoff (1984), has documented a fascinating tradeoff between employees’ access to a unionized voice mechanism, such as a grievance system, and their likelihood of existing the firm. Building on Albert Hirschman's seminal 1970 book that examined exit and voice in the consumer context, Freeman and Medoff argued that lower turnover levels in unionized establishments was the product, among other factors, of employee access to institutionalized voice (Hirschman, 1970; Freeman and Meddoff, 1984). When confronted with dissatisfying working conditions, the authors argued, employees can either leave or exit the firm or use their voice to attempt to address this underlying dissatisfaction. Where voice is a genuine formalized option, use of exit is likely to decline, according to this argument. These findings have been supported by a large number of subsequent studies in a host of unionized contexts (see for example Rees, 1991). Interestingly and relevant to the discussion below, support for an exit-voice tradeoff in the nonunion setting has been weak, at best (see for example Boroff and Lewin, 1997).

As with research on grievance filing, there are clear potential linkages between evidence regarding the relationship between grievance systems and turnover and the organizational behavior research regarding the effects of conflict on group and individual outcomes. For example, this research points to the voice related role that grievance filing activity serves and raises the question as to whether other manifestations of conflict, like those studied by organizational behavior scholars also function as a voice producing mechanism. Do different types of conflict vary in terms of their ability to facilitate voice? In addition, this research also demonstrates the importance of specific organizational arrangements designed to address conflict in enhancing its potential benefits. Does conflict need to be channeled through a formal grievance process in order for it to constitute voice and thereby reduce employee quits? Can 
these grievance system findings help to inform the organizational behavior debate regarding the potential benefits of certain types of conflict?

Industrial relations research has also examined the relationship between workplace conflict, measured as the volume of grievances filed, and firm or plant performance. This research points to a significant negative relationship between formal manifestations of conflict and firm performance. For example, in their seminal study of 25 manufacturing plants within one company, Katz, Kochan, and Weber found that increased grievance filings were associated with lower levels of labor efficiency and quality (Katz, Kochan, and Weber, 1985; also see Katz et al., 1983; Ichniowski, 1986; Cutcher-Gershenfeld, 1991). Conducted at the a different level of analysis and with a different conceptualization of conflict, this research can and should be juxtaposed against the organizational behavior research also linking conflict to performance outcomes.

In addition to documenting the negative relationship between formal manifestations of conflict and firm performance, this research highlighted a large degree of variation in the levels of conflict across different workplace settings. In other words, while conflict may be an inevitable feature of organizational life, organizations vary in terms of its “volume” and prevalence. It is interesting to consider these findings alongside the above discussion regarding the turnover benefits associated with the presence of a unionized grievance system. On the one hand, increased grievance activity appears to be detrimental to firm performance. On the other hand, the presence of a grievance system also appears to serve as a voice mechanism that is associated with decreased exit. It is also interesting to compare these findings regarding the negative effects of conflict at the organizational level with the organizational behavior evidence on the potential performance benefits at the team level. This comparison underscores the 
importance of assessing the effects of conflict at different levels of analysis. It also suggests that the manner in which conflict is conceptualized has important implications. Organizational behavior researchers have paid careful attention to the distinction between different types of conflict, but they have mostly ignored the level of formalization of conflict. Industrial relations scholars, for their part, have not accounted for different types of conflict, and have primarily focused on its formal manifestations without accounting for or capturing more informal expressions. Since both expressions of conflict, formal and informal, are likely to have important organizational and individual consequences, existing theoretical frameworks should account for both.

This disciplinary comparison also supports the argument, advanced throughout this paper, that there is much to be gained, conceptually and empirically, by engaging in interdisciplinary fertilization. Is the negative relationship between grievances and firm performance more pronounced for certain types of conflict, as is suggested by the organizational behavior research? Should the organizational behavior research account for the level of conflict formalizations, which seems to be central to the way in which conflict is conceptualized in the industrial relations literature? Finally, what is the relationship between the industrial relations and organizational behavior operationalization's of conflict? Are informal task, relationship, or process forms of conflict associated with formalized grievances?

Alongside the longstanding interest in conflict and its resolution in the unionized context, industrial relations scholars have increasingly applied their disciplinary lens to emerging practices and trends in the nonunion setting. The rise of alternative dispute resolution (ADR) practices in the nonunion setting beginning in the 1980s represents a dramatic and consequential organizational transformation—one that has influenced internal structures, managerial authority, 
and employee access to voice (for a similar argument see Colvin and Avgar, 2017). As part of this transformation a growing proportion of large firms in the United States and in other developed countries have adopted and implemented various dispute resolution practices such as mediation and arbitration in order to address workplace conflict. In fact, the vast majority of large U.S. firms have some experience using these ADR techniques (Lipsky, Seeber, and Fincher, 2003; Colvin, 2003; Lipsky, Avgar, and Lamare, 2014). More recently nonunion organizations have begun to adopt bundles of conflict management practices in an effort to deal with conflict in a proactive and systemic manner (Lipsky, Seeber, and Fincher, 2003). Recent estimates suggest that approximately one third of Fortune 1000 firms in the United States have adopted, what scholars have referred to as, an integrated conflict management system (Lipsky, Avgar, and Lamare, 2014). Conflict management systems are characterized by an attempt to implement an internally consistent bundle of conflict management practices that is aligned with the firm's overarching conflict management strategic orientation (Lipsky et al., 2003; Lipsky, Avgar, and Lamare, 2016).

The rise of both ADR and conflict management systems in nonunion organizations garnered the attention of industrial relations scholars leading to an interesting disciplinary shift from a traditional, and almost exclusive, focus on conflict resolution in the unionized setting (Avgar et al., 2013; Bendersky, 2007, 2003; Colvin 2003; Eigen \& Litwin, 2014; Ewing, 1989; Fuller, 1978; Lewin, 1987; Lipsky \& Avgar, 2008; Lipsky, Avgar, \& Lamare, 2014; McCabe, 1988; Westin \& Feliu, 1988). This research has been dominated by two overarching research interests. First, early ADR and conflict management systems research provided primarily descriptive accounts of the types of practices adopted by organization and their core procedural characteristics (see for example, Colvin et al., 2006; Lipsky et al., 2003). This body of research 
also examined the organizational usage patterns of different techniques. In doing so, industrial relations scholars documented the central features of different dispute resolution practices and their prevalence.

A second dominant ADR and conflict management systems area of inquiry has focused on adoption drivers (for an example see Colvin, 2003). Fascinated by the dispute resolution pivot made by a significant proportion of nonunion firms, industrial relations scholars have sought to explain this development. What led organizations to cede their traditional managerial authority to deal with and manage conflict by implementing a wide array of increasingly institutionalized practices? This research has advanced a number of proposition about the conflict management shift in nonunion firms. First, some scholars have focused on the external pressures that have led to the adoption of new dispute resolution practices and systems.

For example, scholars have pointed to the increased regulation of the workplace beginning in the 1960s with the passage of landmark civil rights legislation (for a similar discussion see Lipsky et al., 2003). This regulation, in turn, led to a dramatic rise in employment litigation. Organizations, according to this explanation, were motivated by an effort to establish buffers from the external justice system by establishing internal mechanisms to deal with and manage workplace disputes (for a similar review see Lipsky, Avgar, and Lamare, 2014). Unions and collective bargaining represent another example of an external pressures that is proposed to have influenced organizational adoption of ADR and conflict management systems (Colvin 2003). Firms, according to this argument turn to ADR as a means to either avoid unions or as way to substitute for the role that unions may have played in the past (Lipsky et al., 2014).

Second, researchers have pointed to internal organizational changes that have led to a growing reliance on ADR and conflict management systems (Avgar, 2015; Lipsky et al, 2014). 
ADR according to this argument, is depicted as a complementary bundle of practices designed to support the increasingly flat and horizontal organizational structures associated with these changes (Avgar 2015). As firms began to experiment with work systems and practices that provided employees with greater levels of discretion and that promoted problem solving teams, they also required ways to manage and address new forms of conflict that arose out of these structural reconfigurations (Avgar 2015).

Finally, a more recent stream of research has focused on the strategic underpinnings guiding organizational decisions to adopt ADR and conflict management systems (Lipsky, Avgar, and Lamare, 2016). The adoption of specific ADR practices and conflict management systems, is, according to this argument, the product of a firm's strategic orientation (for a review see Lipsky, Avgar, and Lamare, 2016). Put differently, in making conflict management decisions, firms are influenced by the extent to which they believe that specific practices are able to deliver on overarching goals and objectives. The choice of practices is, therefore, not a reactive response to internal or external pressures, but a proactive attempt to advance certain organizational objectives.

As will be discussed below, this stream of industrial relations conflict management research has a number of clear potential linkages with organizational behavior conflict research. First, despite volumes of research examining the features and characteristics of different conflict management practices, there is virtually no evidence regarding their implications for actual of organizational conflict. Partly due to the disciplinary boundaries motivating this paper, we do not know whether the practices implemented as a vehicle to address workplace conflict have any discernable influence on the levels or types of conflict experienced throughout the organization at the individual, group or firm levels. Do specific ADR practices influence the prevalence of 
different types of workplace conflict? Second and as noted above, organizational behavior research has begun to examine contextual factors that influence the manner in which conflict affects team and individual performance. To what extent do organizational conflict management practices moderate the relationship between conflict and performance? Addressing these questions and others that will be discussed below will clearly require the integration of organizational behavior and industrial relations insights.

\section{Pressures of the Legal Environment: Legal Analysis of Organizational Conflict}

\section{Management}

Alongside industrial relations and organizational behavior research, legal scholars have also applied their disciplinary lens to the study of organizational conflict management and the rise of ADR in particular. Not surprisingly, legal scholars have approached the study of organizational management with a different focus and with a different set of underlying research questions. Much of this research has centered on the adequacy associated with different conflict management practices from a broader societal perspective. Given this disciplines careful attention to public policy questions around issues related to justice and fairness, legal scholars have engaged in an ongoing debate regarding the ability of dispute resolution practices such as mediation and arbitration to serve as substitutes for the traditional judicial system (see for example Fiss, 1984; Stone, 1996; Edwards, 1986). A number of core themes emerge from this body of literature.

First, like their industrial relations colleagues, some legal scholars have explored the link between legal and regulatory pressures and the adoption of organizational conflict management practices and systems (see for example Sutton et al., 1994; Edelman, 1990). This research complements the industrial relations literature examining adoption pressures, but provides a 
much more nuanced and detailed analysis of the ways in which changes in the external legal and normative environments have shaped organizational internal legal responses through the adoption of nonunion grievance systems (Sutton et al., 1994). While industrial relations scholars have examined the direct link between litigation related pressures and the adoption of ADR and conflict management systems, legal scholars have tried to identify the mechanisms through which the external environment affects internal conflict management structures. For example, Edelman (1990) analyzes longitudinal data from 52 firms and identifies the nature of the relationship between organizations and the external legal environment as a central predictor of ADR adoption patterns. Organizations, according to this argument are motivated by efforts to enhance their perceived legitimacy by demonstrating a responsiveness to due process and fairness concerns in the workplace. As legal and regulatory environments shifted in a manner that highlighted procedural shortcomings, some organizations turned to ADR in an effort to restore their perceived legitimacy. Variation in organizational conflict management portfolios is the product, therefore of differences in organizational need for legitimacy (Edelman, 1990). As such, organizations that are closer to the public sphere and have a stronger sensitivity to the external legal environment are more likely to adopt internal nonunion conflict management practices (Edelman, 1990). Edelman’s argument, supported by her findings, paints a rather critical portrait of nonunion ADR and conflict management systems. If firms are motivated, primarily, by their efforts to gain legitimacy, their commitment to and support of the genuine implementation of these practices may be challenged. Nonunion conflict management practices, therefore, may serve as a symbolic rather than substantive role.

While this research has had some influence on the industrial relations literature, its integration has, to date, been limited. Nevertheless, there are clear ways in which this focus on 
the legal environment can inform and enrich conflict and conflict management research in other disciplines. First, this research suggests that the link between the environment and the pressure it places on organizations is more complex than might be acknowledged by industrial relations research. This research, therefore, helps to identify categories of mechanisms through which the environment affects organizational decisions about how to manage internal conflict. On the other hand, while the legal scholarship has been much more detailed in its depiction of the ways in which the external environment shapes organizational use of ADR, its description of actual dispute resolution mechanisms is rather limited. Thus, a second benefit associated with the integration of disciplinary insights rests on the combination of the nuanced description of environmental pressures, offered by legal scholarship, with the detailed and well-developed conceptualization of ADR practices, provided by industrial relations scholars. Finally, these legal insights can also inform organizational behavior research on conflict. To what extent do external normative and regulatory pressures affect the nature of frontline employee conflict? Do changes in the legal environment have an influence on the way in which employees perceive relational dynamics at the group level? These questions have not, to date, been addressed, but they get at the heart of conflict researcher's ability to paint a more complete portrait of the linkages across levels of analysis.

A second dominant theme that emerges from the legal conflict resolution research deals with the appropriateness of ADR as a substitute to courts. Can ADR practices guarantee the same procedural protection and substantive remedies as those offered by the traditional justice system? This question has given rise to an extensive and heated debate regarding both the conceptual underpinnings of ADR and the empirical evidence comparing outcomes across private and public dispute resolution forums (see for example, Fiss, 1984; Stone, 1996; Edwards, 1986). For 
example, in his seminal critique of ADR as a vehicle to resolve disputes, not exclusive to the workplace, Owen Fiss raises a number of fundamental concerns about the substitution of settlement for justice (Fiss, 1983). Central among these concerns is the absence of careful attention to power imbalances between the parties. Other legal scholars focusing on ADR in the employment context have raised similar concerns about the use of dispute resolution practices to resolve workplace conflict in the nonunion setting. In her critique of employment arbitration, Katherine Stone maintains that without the backing of a union, mandatory arbitration disadvantages employees. In fact, employment arbitration has become a lightning rod for this broader ADR debate. One of the central employment arbitration challenges rests on the advantage it provides to firms given their repeat player role (Colvin, 2011; Bingham, 1997). Repeat players, or those actors that have multiple arbitration experiences, are, according to critics, better positioned to benefit from this dispute resolution process.

This conceptual critique of ADR and arbitration in particular has received significant empirical support over the past two decades. In one of the first empirical attempts to provide support for the repeat player effect, Lisa Bingham (1997) analyzed 270 arbitration cases administered by the American Arbitration Association (AAA) and found a strong repeat player effect. When the employer was a repeat player and the employee was not, the employee was both more likely to lose the case or to receive a smaller award. In his 2011 study of 3,945 AAA case, Alexander Colvin finds additional support for the inadequacy of arbitration as an alternative to the courts. Specifically, Colvin finds significant differences in terms of both the employee win rates and the award amounts were both lower in arbitration as compared to the courts. Colvin also extends Bingham’s repeat player findings documenting that employers with previous arbitration experience fare better than those that do not. Furthermore, Colvin finds that 
employers with previous experience with the same arbitrator have an additional advantage, thereby suggesting that the repeat player effect is not simply a function of organizational characteristics such as size.

Alongside research documenting arbitration's shortcomings, the benefits of ADR and arbitration are supported in a body of empirical legal scholarship. First, there are legal scholars who highlight the advantages associated with interest-base practices such as mediation, arguing that the flaws inherent to arbitration should not undermine the potential benefits associated with other ADR techniques. For example, Lisa Bingham, cited above for her work critical of arbitration, has provided extensive empirical evidence regarding the use of mediation to address workplace conflict (Bingham 2009).

Bingham evaluated the United States Postal Services’ mediation program and documented both procedural and substantive advantages and the various outcomes that suggest that this approach benefited both the employer and the employees. Second, in addition to legal scholarship advancing other ADR techniques, there are legal scholars who contend that mandatory employment arbitration is, in fact, fair and preferable to the traditional court system. Samuel Estreicher, a staunch supporter of mandatory arbitration, has argued that this form of ADR provides employees who might otherwise not have real access to the court systems, due to a lack of resources or perceived monetary value of their case, with a fair and adequate alternative. Arbitration, according to Estreicher was, therefore, associated with increased access to justice, not less. Other legal scholars have refuted empirical evidence suggesting that the outcomes associated with arbitration do not compare well with those attained in court (see for example Eisenberg and Hill, 2003). Eisenberg and Hill (2003) argue that research documenting lower awards in arbitration compared to the court systems use inadequate comparison groups 
using data on low wage employees covered by mandatory arbitration agreements and higher paid employees with court rulings.

This empirical debate regarding the procedural and substantive adequacy of ADR has a number of implications for the potential interdisciplinary study of conflict and its management in organizations. First, much of this legal debate has largely ignored the organizational context in which a given arbitration system is implemented. In other words, there is room for this legal research to incorporate industrial relations evidence on both different types of conflict management practices that reside alongside arbitration and on the broader organizational arrangements that complement these practices. Second, building on this legal research, industrial relations research should consider outcomes that extend beyond the traditional organizational measures when studying conflict management practices. Thus, industrial relations research should explore broader fairness and justice related outcomes associated with organizational conflict management practices. At the same time, legal scholarship might benefit from the expansion of outcomes used to compare traditional and alternative methods to resolve workplace conflict. In doing so, this research can begin to bridge insights gleaned from this parallel body of legal scholarship. A recent effort to do so can be found in Eigen and Litwin’s (2014) article that examines the organizational justice perceptions associated with a dispute resolution system in a large retail organization.

\section{Blinded by Disciplinary Boundaries: The Scholarly Costs of Limited Integration}

This review of conflict research across three different disciplines points to the clear scholarly costs associated with the limited integration of insights across these manufactured boundaries. While each of these research streams has produced volumes of valuable findings pertaining to conflict and conflict management, there is still a great deal that we do not know 
due, in large part, to unnecessary disciplinary dividing lines. Thus for example, organizational behavior scholars who have focused on conflict as an independent variable have provided limited evidence on the actual antecedents to organizational conflict. They have also ignored a host of organizational arrangements and practices that are likely to moderate the relationship between conflict a group and individual outcomes. Industrial relations scholars, for their part, have focused on the organizational context and on the conflict management practices implemented in both the union and nonunion setting, but have provided limited evidence on how such factors influence the nuanced manifestation of actual conflict experienced on the frontlines. This research has, to date, not documented the relationship between specific conflict management practices and employees' concrete experiences of conflict in the workplace. This research has also been limited in the attention it has given to ways in which external pressures, such as the legal system, might affect internal organizational choices and outcomes. Finally, legal scholars, who have debated the procedural and substantive adequacy of different dispute resolution practices with a heavy emphasis on arbitration, have not fully addressed or acknowledged the effects of internal organizational practices and arrangements.

Taken together, each of these three disciplines offers detailed evidence on the core pieces of the organizational conflict and conflict management puzzle. Nevertheless, in the absence of integration, these insights remain limited in their ability to fully capture the intricacies necessary for a more comprehensive analysis of conflict and its management. For a summary of disciplinary limitations in the study of conflict and conflict management see Table 2. What is at the heart of existing disciplinary barriers that hinder integration? One of the culprits of this lack of integration rests on the fact that observations in each of these disciplines are made at different levels of analysis with a focus on fundamentally different dimensions of conflict or conflict 
management. What is, therefore, needed, I argue, is a theoretical framework with the capacity to link conflict and conflict related management findings across different levels of analysis and, at the same time, acknowledge the importance of external pressures and identifying a range of outcome categories. In what follows, I present one such framework-a three tiered industrial relations framework — and illustrate its capacity to establish bridges across the disciplinary barriers outlined above by addressing each of these needs.

--Insert Table 2 about here--

Integrating Insights: Leveraging an Industrial Relations Framework to Integrate Conflict Insights across Disciplines

Review of the Strategic Choice Framework

As noted above, the three tiered strategic choice framework advanced by Kochan, Katz and McKersie (1986) and building on Kochan, McKersie, and Cappelli (1984) is, arguably, uniquely suited as a vehicle through which to explore conflict and conflict management linkages across disciplines. This framework emerged in the mid-1980s as part of industrial relations scholars' efforts to explain the dramatic changes taking place in within a growing proportion of American firms, which included new organizational arrangements and practices (for a similar review of this framework see Avgar and Kurivilla, 2012). In their attempt to understand this changing organizational landscape, Kochan and colleagues set forth a framework that departed from traditional structural and reactive explanations for industrial relations activities and outcomes. At the heart of this framework is the argument that industrial relations outcomes are the product of a series of strategic choices that different actors make across three levels of 
activity (for a discussion see Avgar and Kuruvilla, 2012). As such, this framework rests on three important propositions.

--Insert Figure 1 about here--

First, Kochan and colleagues (1986 and 1984) maintained that industrial relations outcomes are not solely a function of structural features of the relationship between labor management and their reactive responses to external pressures. Rather, industrial relations actors, union leaders, top management, middle management, and supervisors, have a range of choices when making managerial and organizational decisions. As such, one cannot understand industrial relations processes and outcomes without a clear understanding of the strategic choices made by key actors within the system (for a similar discussion see Avgar and Kuruvilla, 2012). Put differently, the contours and consequences of a given industrial relations system are, to a large extent, a function of the strategic choices that labor and management actors make.

In addition to the emphasis on strategic choice, this framework also rests on the proposition that industrial relations activity occurs across three central and interrelated levelsstrategic, functional, and workplace. At the strategic level, union leaders and top management set forth their overarching and long-term goals and objectives. This level activity includes, among other things, decisions about how to engage labor or management counterparts, about the firm's overarching business strategy, and about which organizational arrangements workplace practices are best suited to advance these strategies. The functional level, which received a great deal of attention in the traditional industrial relations literature represents the arena in which the parties actually engage one another and establish the core features of their relationship. In the context of industrial relations, this is where bargaining and changes to the labor management relationship take place. Finally, the workplace level represents the arena in which the day-to-day frontline 
interactions occur. This level of activity includes the relational dynamics that emerge both between employees and supervisors, but also among peers.

Taken together, this three tiered framework supports the argument that industrial relations outcomes are the product of interrelated strategic choices made by key actors across three levels of activity and in response to a host of external pressures. The framework's central propositions make it especially applicable to the study of conflict and its management. First, in contrast to the study of conflict and conflict management, the actual manifestations of these play out across multiple levels of organizational activity. Second, like other workplace phenomena, conflict requires employment relations actors to make strategic decisions about how best to manage and deal with conflict. Third, strategic decisions about how to deal with and manage conflict are affected by a host of external pressures and environmental constraints. Fourth, actions and decisions made at different levels of organizational activity influence one another. Fifth, expressions of conflict and efforts to manage it have implications for a host of outcomes at different levels of organizational activity. Building on this proposed fit between the framework and the study of conflict, I demonstrate its ability to integrate disciplinary insights and to highlight underexplored and important avenues for research. For a summary of theoretical linkages based on this framework, see Figure 2.

--Insert Figure 2 about here--

Applying the Strategic Choice Framework to Organizational Conflict and Conflict Management

\section{Environmental Pressures and Constraints and Organizational Conflict and Conflict}

Management. While the strategic choice framework departs from the traditional reactive and deterministic approach to understanding industrial relations systems it does fully acknowledge 
the central role that the environment plays in shaping the range of choices that actors face. Actors have strategic choice, but this choice is constrained by the pressures and opportunities associated with the given environmental context. As noted above, both industrial relations and legal scholars have been attuned to the role that the environment plays in influencing organizational conflict management decisions with a particular emphasis on pressures associated with the legal environment. In addition, industrial relations scholars have identified other environmental factors influencing conflict management choices, including potential unionization and market pressures. Nevertheless, the strategic choice framework points to a number of underdeveloped linkages between the environment and organizational conflict and conflict management. First, industrial relations and legal scholars have, to date, examined a relatively narrow set of environmental pressures affecting organizational conflict management. Alongside the study of the aforementioned pressures, conflict scholars should expand the types of environmental factors that are likely influencing actors’ strategic choices. The strategic choice framework highlights the potential role that additional factors such as technological change, regulatory pressures, financial pressures, and industry trends, are likely to play in affecting internal organizational decisions (Kochan et al., 1984). Given that these pressures influence a host of organizational choices and internal dynamics, it is reasonable to propose a relationship between a broader array of environmental factors and the concrete manifestations of conflict and conflict management in organizations.

Theoretical Linkage 1: Future research should expand the range of environmental pressures affecting organizational conflict and conflict management beyond the existing factors.

Second, much of the current research on the effects of the environment on conflict and conflict management have focused on the functional level, or on the formal conflict management 
practices implemented by firms. For example, Colvin (2003) examines the effects of litigation and unionization threats on the adoption of arbitration and peer review processes. Lipsky and colleagues (2003), who also identify a number of environmental pressures, link these to the formal adoption of specific conflict management practices. Leveraging the strategic choice framework highlights the need to focus on the two additional levels of organizational activity. First, how do environmental pressures influence conflict and conflict management at the strategic level? Do environmental pressures affect the broader conflict and conflict management strategic goals of the firm? Do these pressures shape different overarching types of conflict at the strategic level? While existing research has provided some answers to these questions (see for example, Lipsky 2003), there is a great deal of room for a more comprehensive assessment of the ways in which the external environments affects conflict and conflict management at the strategic level. Second, there is very little, if any, existing evidence as to how the external environment affects conflict and conflict management at the workplace level. How do external pressures affect the actual manifestation of conflict for frontline employees? Do such pressures influence the informal resolution of conflict between peers? By distinguishing between levels of organizational activity, the strategic choice framework facilitates the bridging of disciplinary boundaries. Much of what we know about conflict at the workplace level is generated by organizational behavior scholars while evidence on environmental pressures has been accumulated by industrial relations and legal scholars. If scholars are to advance our understanding of how environmental pressures affect conflict and conflict management at the workplace level they will need to bridge these bodies of literature. 
Theoretical Linkage 2: Future research should examine the link between environmental pressures and conflict across each of the three levels of organizational activity with a particular emphasis on both the strategic and workplace levels.

Third and building on the above discussion, existing research has documented a link between environmental pressures and organizational conflict management with little attention to the manner in which conflict is affected by external factors. This is, in part, a function of the absence of evidence related to the manner in which environmental pressures affect conflict and conflict management at the workplace level, but there is also a need to examine how functional and strategic level conflicts are shaped by dynamics taking place outside the firm.

Theoretical Linkage 3: Future research should examine the link between environmental pressures and manifestations of conflict at each of the three levels of organizational activity

Finally, we know relatively little about the mechanisms through which the environment affects conflict and conflict management within organizations. As noted above, legal scholars have provided a nuanced analysis of the mechanisms linking legal pressures and the adoption of organizational conflict management practices. Nevertheless, this type of analysis has been, for the most part, limited to legal pressures with far less attention given to mechanisms that link the host of other environmental pressures and conflict and conflict management across the multiple levels of organizational activity.

Theoretical Linkage 4: Future research should expand the focus on the mechanisms through which different environmental factors affect conflict and conflict management across each of the three levels of organizational activity. 
The Strategic Level of Organizational Activity and Conflict and Conflict Management. One of the central insights advanced by the strategic choice framework is the need to better understand dynamics that take place at the strategic level of organizational activity. Top management and union leadership make a host of broad and long-term decisions that influence both the functional and workplace levels as well as central outcomes. As such, key conflict and conflict management decisions are likely to be made at this level of organizational activity—decisions that, to date, have received limited scholarly attentions. First, emphasis on the strategic level highlights the need to better document organizations' overarching conflict orientation. What is the firm's general approach to conflict? Does an organization's top management view conflict as a threat that must be eradicated or is it viewed as having some organizational benefits? We know from the organizational behavior literature that conflict can, under certain circumstances, provide a host of team level benefits. What we do not yet know is the extent to which organizations vary in terms of their strategic level orientations towards conflict and, more importantly, whether these orientations matter for a host of outcomes.

Theoretical Linkage 5: Future research should examine strategic level variation in terms of conflict approach and orientation.

Second, in addition to variation in terms of conflict orientation, firms are also likely to vary when it comes to their overarching conflict management orientation. Do firms have different strategic orientations regarding the manner in which they manage conflict? Do organizations vary when it comes to how they approach and deal with organizational conflict? What are the strategic level factors that explain variation in the nature of an organization's approach to conflict management? Recent industrial relations research has begun to focus on different strategic level orientations towards conflict management (see for example Lipsky and 
Avgar, 2008; Lipsky, Avgar and Lamare, 2014), but this line of inquiry is still in its infancy with many additional questions to be explored. In addition, organizational behavior scholars have identified different individual and group level conflict management styles (see for example Rahim, 2001, 1983). Do these styles hold at the organizational level? Do the conflict management styles of strategic level actors and groups affect broader organizational approaches to conflict management? Conflict management researchers need to build on the emerging literature examining strategic level choices.

Theoretical Linkage 6: Future research should examine strategic level variation in terms of conflict management approach and orientation.

Third, it is not surprising that given the limited conflict management research at the strategic level there is virtually no evidence linking strategic level conflict management choices and organizational outcomes. Nevertheless, this linkage is central to understanding the manner in which conflict plays out across different levels of organizational activity. Does a firm's strategic orientation towards conflict and conflict management affect firm level performance? We know from industrial relations research that actual grievance activity affects firm performance, but we do not know whether there are consequences to different strategic approaches to conflict and the way it is managed. Do these orientations affect other outcomes at the group and individual level? As part of a focus on the strategic level of activity, scholars should also begin to link conflict and conflict management choices to a host of firm, group, and individual level outcomes.

Theoretical Linkage 7: Future research should examine the relationship between strategic level variation and outcomes at different level of analysis. 


\section{The Functional Level of Organizational Activity and Conflict and Conflict Management.}

Choices made at the strategic level get implemented at the functional level of organizational activity. This level of activity has been the focus of much of the existing industrial relations conflict management research. As noted above, scholars have examined the adoption and implementation of different conflict management practices. Research on conflict management at this level of activity has also assessed usage patterns across different types of practices and procedures (citation). Situating this research within the strategic choice framework points to a number of linkages that have not yet been fully explored. First, and building on the above subsection, we know relatively little about the relationship between strategic level considerations and functional level practices and procedures. How do strategic choices made by top management influence the range of conflict management practices made available to employees and their usage pattern? Does the strategic level orientation influence the manner in which functional level conflict management decisions are made? Do functional level implementation, adoption and usage patterns affect strategic level conflict management decisions?

Theoretical Linkage 8: Future research should assess the relationship between conflict management decisions at the strategic level and adoption, implementation, and usage patterns at the functional level.

Second and highlighted in the review of the literature above, there is limited conceptual and empirical linkages between functional level decisions and activities and conflict at the workplace level. This absence of research is, to a large extent, the product of the aforementioned disciplinary divide between industrial relations and organizational behavior scholars. As noted above, we know very little about the manner in which conflict management practices, implemented and managed at the functional level and studied by industrial relations scholars 
affect the manifestations of conflict at the workplace level, which has been examined by organizational behavior scholars. What is the relationship between different conflict management practices and expressions of frontline employee conflict? Do different formal conflict management practices affect the ways in which frontline employees and supervisors deal with conflict informally? Do conflict patterns at the workplace level affect the usage patterns of conflict management practices at the functional level? These questions point to the many potential gains of pursuing conflict research linking functional and workplace level activities.

Theoretical Linkage 9: Future research should assess the relationship between conflict management practices and patterns at the functional level and conflict expressions at the workplace level.

Third, another avenue of research stemming from the focus on the functional level of activity relates to the relationship between conflict management practices and other organizational arrangements and work practices. Industrial relations scholars have examined the role that certain work practices, such as high performance work systems, have played in explaining the adoption of ADR and conflict management systems (see for example, Colvin, 2004). There is far less evidence about how these different functional level practices and arrangements interact. Do certain conflict management practices complement specific bundles of work practices? Are organizational outcomes affected by the level of alignment between conflict management and work practices?

Theoretical Linkage 10: Future research should assess the relationship between work practices and organizational arrangements and conflict management systems and practices. 
Finally, as with the strategic level of organizational activity, there is a need for empirical evidence linking practices and processes at the functional level and organizational outcomes. As noted above, industrial relations research has, for the most part, not examined the relationship between conflict management practices and measures of organizational performance. If researchers are to assess the extent to which firms that adopt a set of consistent conflict management practices gain an advantage over firms that adopt a traditional approach, they will need to establish an empirical link between practices and a set of outcomes. In addition to firm performance there is also a need for research on a host of other outcomes at different levels of analysis including workplace level consequences. Thus for example, are different conflict management practices associated with employee attitudes, perceptions, or behaviors?

Theoretical Linkage 11: Future research should assess the relationship between conflict management practices and patterns and organizational outcomes at different levels of analysis.

\section{The Workplace Level of Organizational Activity and Conflict and Conflict Management. As}

noted above, much of the evidence on the conflict and conflict management at the workplace level is the product of the organizational behavior research reviewed above. This research provides evidence on the individual and group level conflict and conflict management and associated consequences. Situating this research within the strategic choice framework highlights a number of areas that require additional conceptual and empirical work. First, the vast majority of this research has focused on the role that conflict at the workplace level plays as independent variables predicting group or individual outcomes. As noted above, there is far less research examining conflict and conflict management as a dependent variable. What are the antecedents to different types of conflict? Do some of these antecedents reside across different levels of organizational activity? This is an area where industrial relations research can be especially 
useful give existing evidence on organizational practices and arrangements that likely affect the expressions of conflict and its management.

Theoretical Linkage 12: Future research should assess the relationship between individual, group, and organizational level independent variables and different types of conflict as dependent variables.

Second and as noted above, the strategic choice framework argues for the interrelationship across levels of organizational activity. As such, there is a need to assess the extent to which conflict and conflict management at the workplace level affect patterns and practices at the functional level and choices at the strategic level.

Theoretical Linkage 13: Future research should assess the relationship between conflict management at the workplace level and patterns and practices at the functional level and choices at the strategic level.

Finally, although organizational behavior research has provided for a wealth of empirical evidence on the relationship between different forms of conflict and group and individual level outcomes, there is virtually no research on the effect of workplace level conflict on organizational level outcomes. Do organizations with higher levels of different types of conflict vary in terms performance and productivity? Industrial relations research has supported the general negative link between the number of grievances in the union setting and performance, but this line of inquiry has not been pursued within the organizational behavior research with nuanced measures of conflict categories outside the grievance system context.

Theoretical Linkage 14: Future research should assess the relationship between workplace level conflict and organizational outcomes at different levels of analysis. 


\section{Conclusion: Towards an Integrated Research Agenda}

The goal of this paper was to highlight the theoretical and empirical costs associated with the fragmented study of conflict and its management across three disciplines and to propose a framework capable of offering an integrated path forward. As noted at the outset, conflict is an inextricable feature of organizational life and, as such, has received a great deal of scholarly attention. Nevertheless, in the absence of a framework allowing scholars and practitioners to link insights and findings across diverse disciplinary domains, the contribution of these substantial bodies of literature is limited in its ability to advance theory and practice.

One of the challenges associated with the integration of conflict research rests on the diverse disciplinary areas of focus, levels of analyses, and underlying assumptions. Yet, these barriers should not obscure the overarching goal of better describing and explaining the manifestation of conflict within organizations. In an effort to do so, I have proposed use of a longstanding industrial relations framework, which is uniquely suited to this task. The three tiered frameworks described in detail above captures organizational activity, like conflict, across multiple level of analysis, accounts for the inherent interdependence across levels, highlights the role that environmental factors play, and helps to position existing research in a manner that clarifies the range of relevant outcomes.

As illustrated above, situating existing research across disciplines within this framework helps to both flesh out the manner in which each body of research is connected to other literatures, thereby pointing to areas of potential synthesis and cross-pollination. Furthermore, doing so also outlines the many linkages and research questions that have been, for the most, ignored as a result of the aforementioned fragmentation. This paper, therefore, contributes to 
existing conflict and conflict management scholarship by developing a foundation upon which to advance an integrated research agenda.

Table 1: Summary of Disciplinary Conflict and Conflict Management Insights

\begin{tabular}{|c|c|c|}
\hline Organizational Behavior & Industrial Relations & Law \\
\hline $\begin{array}{l}\text { Distinguishes } \\
\text { between different } \\
\text { types of conflict }\end{array}$ & $\begin{array}{l}\text { Documents } \\
\text { antecedents to } \\
\text { grievance filings }\end{array}$ & 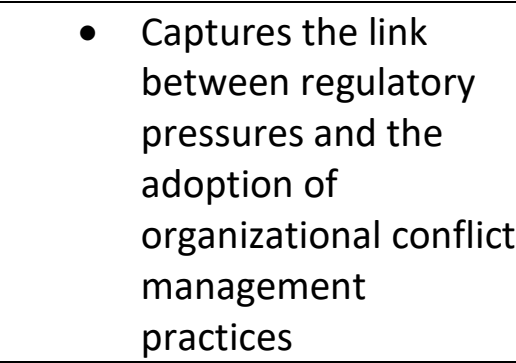 \\
\hline $\begin{array}{l}\text { Documents conflict's } \\
\text { potential positive } \\
\text { effect on } \\
\text { organizational } \\
\text { outcomes as a } \\
\text { function of type }\end{array}$ & $\begin{array}{l}\text { Provides evidence } \\
\text { regarding } \\
\text { consequences } \\
\text { associated with the } \\
\text { institutionalization of } \\
\text { employee voice } \\
\text { through the grievance } \\
\text { system }\end{array}$ & $\begin{array}{l}\text { Documents the effect } \\
\text { of the external legal } \\
\text { environment on } \\
\text { internal firm } \\
\text { approaches to dealing } \\
\text { with conflict }\end{array}$ \\
\hline $\begin{array}{l}\text { Recognizes the role } \\
\text { that contextual } \\
\text { factors affect the } \\
\text { relationship between } \\
\text { conflict and } \\
\text { performance } \\
\text { outcomes }\end{array}$ & $\begin{array}{l}\text { - Substantiates the } \\
\text { negative effects of } \\
\text { grievances on firm } \\
\text { performance }\end{array}$ & $\begin{array}{l}\text { - Compares the } \\
\text { adequacy of } \\
\text { organizational conflict } \\
\text { management } \\
\text { practices to } \\
\text { traditional legal } \\
\text { approaches }\end{array}$ \\
\hline $\begin{array}{l}\text { Provides evidence for } \\
\text { variation in terms of } \\
\text { Individual and groups' } \\
\text { overarching conflict } \\
\text { management styles }\end{array}$ & $\begin{array}{l}\text { Describes and } \\
\text { provides explanations } \\
\text { for the rise of } \\
\text { alternative dispute } \\
\text { resolution and } \\
\text { conflict management } \\
\text { systems }\end{array}$ & $\begin{array}{l}\text { Provides evidence } \\
\text { regarding procedural } \\
\text { shortcoming } \\
\text { associated with } \\
\text { specific conflict } \\
\text { management } \\
\text { practices }\end{array}$ \\
\hline
\end{tabular}


Table 2: Summary of Disciplinary Conflict and Conflict Management Limitations

\begin{tabular}{|c|c|c|}
\hline Organizational Behavior & Industrial Relations & Law \\
\hline $\begin{array}{l}\text { Relative disregard for } \\
\text { individual level } \\
\text { consequences } \\
\text { associated with } \\
\text { conflict }\end{array}$ & $\begin{array}{l}\text { Grievances as the } \\
\text { dominant/exclusive } \\
\text { manifestation of } \\
\text { workplace conflict }\end{array}$ & $\begin{array}{l}\text { - Limited description of } \\
\text { the contours of } \\
\text { different dispute } \\
\text { resolution practices }\end{array}$ \\
\hline $\begin{array}{l}\text { - } \text { Limited evidence } \\
\text { regarding } \\
\text { antecedents to } \\
\text { different types of } \\
\text { conflict }\end{array}$ & $\begin{array}{l}\text { Limited distinction } \\
\text { between different } \\
\text { types of grievances } \\
\text { and their associated } \\
\text { consequences }\end{array}$ & $\begin{array}{l}\text { - Does not address the } \\
\text { link between external } \\
\text { legal pressures and } \\
\text { informal } \\
\text { manifestations of } \\
\text { conflict }\end{array}$ \\
\hline $\begin{array}{l}\text { - Narrow focus on } \\
\text { contextual factors } \\
\text { that likely influence } \\
\text { the effect that conflict } \\
\text { has on organizational } \\
\text { outcomes }\end{array}$ & $\begin{array}{l}\text { - Primary focus on the } \\
\text { formal expressions of } \\
\text { conflict }\end{array}$ & $\begin{array}{l}\text { - Lack of attention to } \\
\text { the organizational } \\
\text { context in which } \\
\text { different dispute } \\
\text { resolution practices } \\
\text { are embedded }\end{array}$ \\
\hline $\begin{array}{l}\text { - Lack of attention to } \\
\text { organizational and } \\
\text { environmental factors } \\
\text { that affect individual } \\
\text { and group responses } \\
\text { to conflict }\end{array}$ & $\begin{array}{l}\text { Absence of a link } \\
\text { between different } \\
\text { conflict management } \\
\text { practices and } \\
\text { outcomes }\end{array}$ & $\begin{array}{l}\text { Focuses on a narrow } \\
\text { set of outcomes } \\
\text { associated with } \\
\text { dispute resolution } \\
\text { practices }\end{array}$ \\
\hline
\end{tabular}


Figure 1: A Three Tiered Framework for the Study of Conflict and Conflict Management

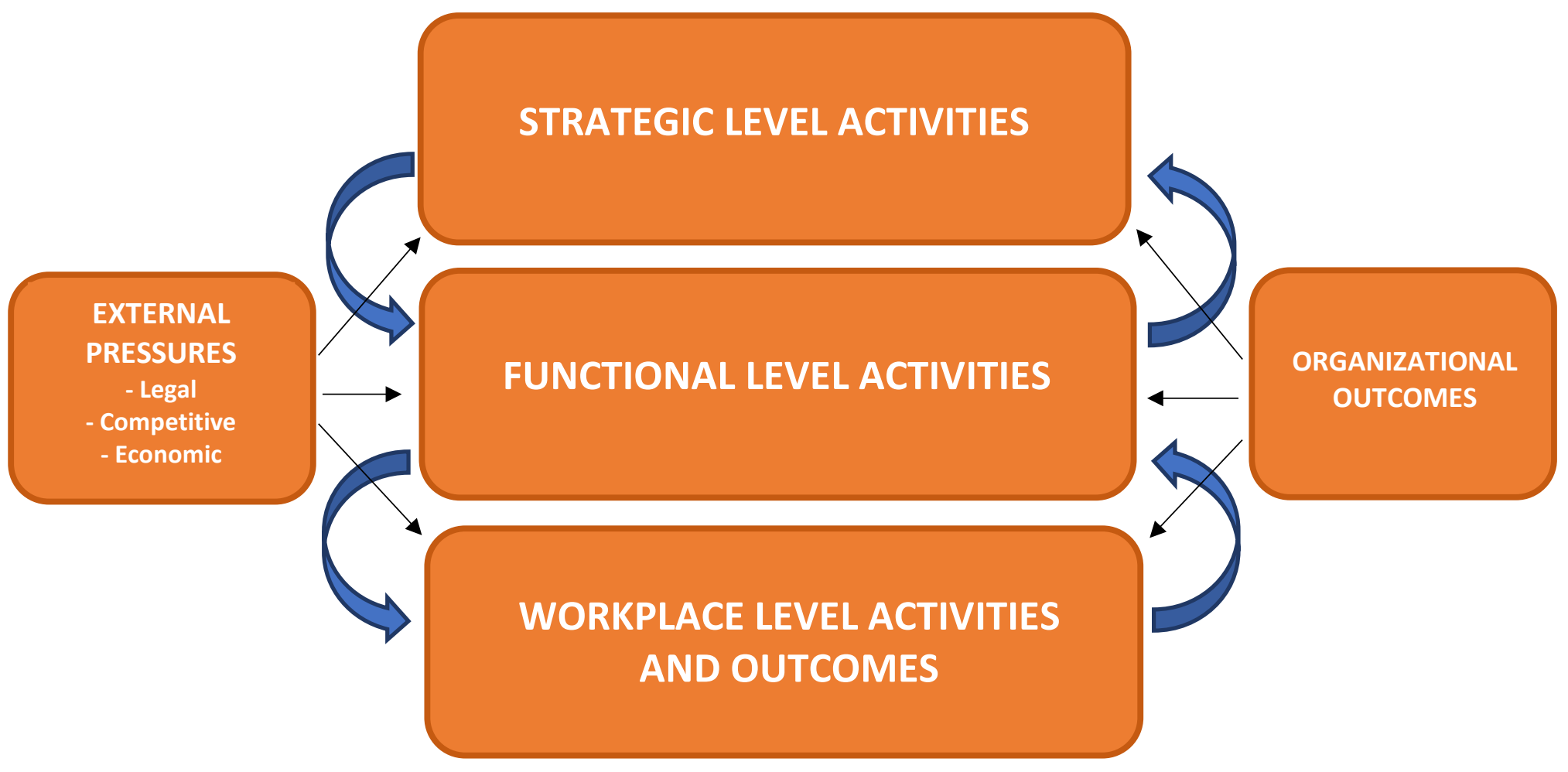


Figure 2: A Three Tiered Framework for the Study of Conflict and Conflict Management:

\section{Theoretical Linkages}

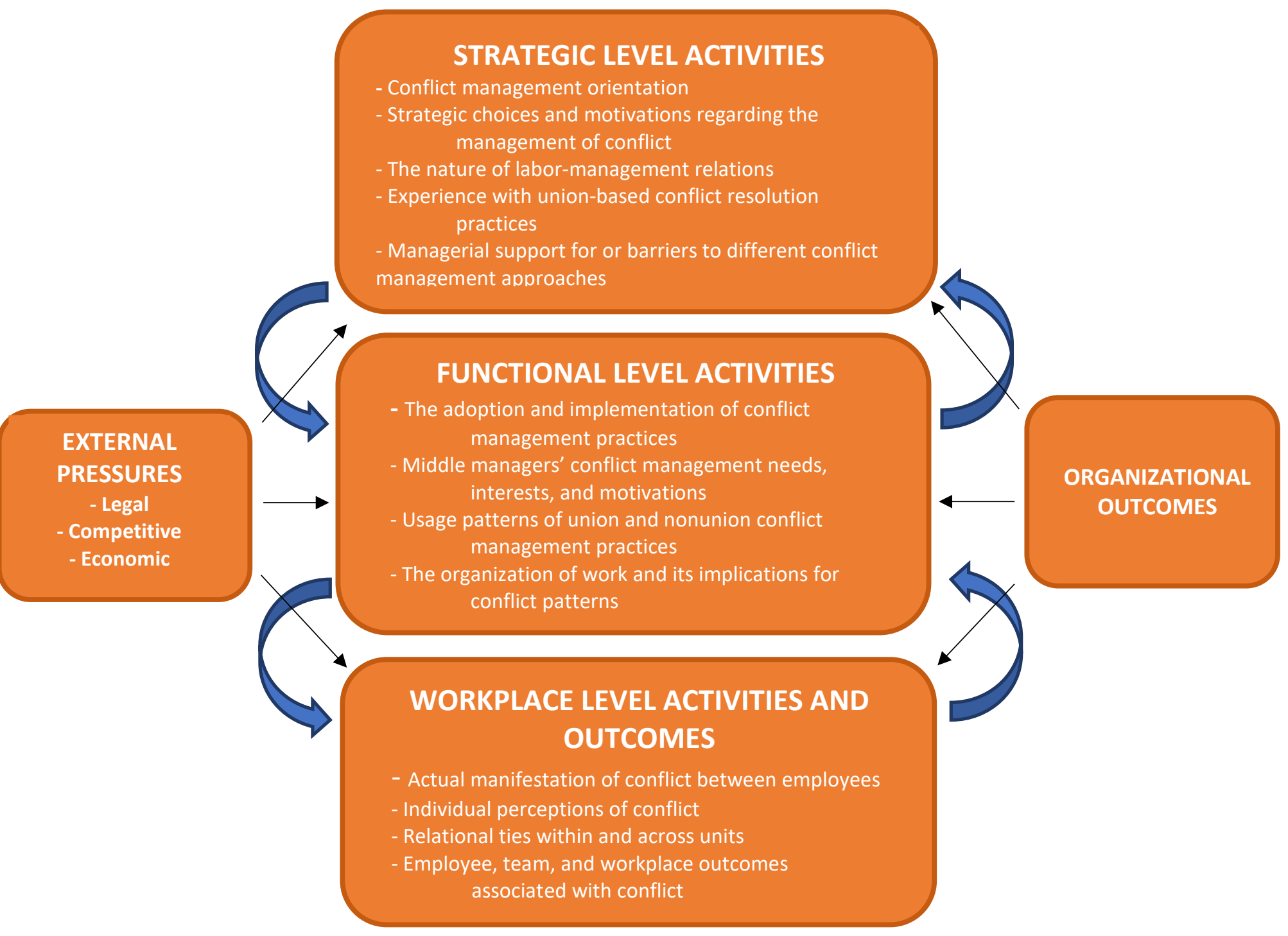




\section{References}

Amason, A. C. 1996. Distinguishing the effects of functional and dysfunctional conflict on strategic decision making: Resolving a paradox for top management teams. Academy of Management Journal, 39(1): 123-148.

Amason, A. C., and Sapienza, H. J. (1997). The effects of top management team size and interaction norms on cognitive and affective conflict. Journal of Management, 23(4), 495-516.

Avgar, Ariel C., and Sarosh Kuruvilla. 2011. Dual alignment of industrial relations activity: From strategic choice to mutual gains. Advances in Industrial and Labor Relations, 18: 1-39.

Barbash, J. 1984. The Elements of Industrial Relations. Madison: The University of Wisconsin Press.

Bemmels, B., \& Foley, J. R. 1996. Grievance procedure research: A review and theoretical recommendations. Journal of Management, 22(3): 359-384.

Bendersky, C. 2007. "Complementarities in Organizational Dispute Resolution Systems: How System Characteristics Affect Individuals' Conflict Experience." Industrial and Labor Relations Review, Vol. 60, No. 2, pp. 204-224.

Bendersky, C. 2003. "Dispute Resolution Systems: A Complementarities Model." Academy of Management Review, Vol. 28, pp. 643-656.

Bingham, L. B. 1997. Employment arbitration: The repeat player effect. Employee Rights and Employment Policy Journal, 1: 189-220.

Boroff, E. K. and Lewin, D. 1997. "Loyalty, Voice, and Intent to Exit A Union Firm: A conceptual and Empirical Analysis." Industrial and Labor Relations Review, Vol. 51, No. 1, pp. 50-63.

Colvin, A. J. 2011. An empirical study of employment arbitration: Case outcomes and processes. Journal of Empirical Legal Studies, 8(1): 1-23.

Colvin, A. J. 2003. The dual transformation of workplace dispute resolution. Industrial Relations: A Journal of Economy and Society, 42(4): 712-735.

Colvin, A. J., Klaas, B., \& Mahony, D. 2006. Research on alternative dispute resolution procedures. Contemporary issues in employment relations, 103-147.

Cutcher-Gershenfeld, J. 1991. The impact on economic performance of a transformation in workplace relations. Industrial \& Labor Relations Review, 44(2): 241-260. 
De Dreu, C. K. W., \& Weingart, L. R. 2003. Task versus relationship conflict, team performance, and team member satisfaction: A meta-analysis. Journal of Applied Psychology, 88(4): 741-749.

De Dreu, C. K. W. 2006. When too much and too little hurts: Evidence for a curvilinear relationship between task conflict and innovation in teams. Journal of Management, 32(1): 83107.

De Wit, F. R. C., Greer, L. L., \& Jehn, K. A. 2012. The paradox of introgroup conflict: A metaanalysis. Journal of Applied Psychology, 97(2): 360-390.

Edelman, Lauren B., Howard S. Erlanger, and John Lande. 1993. Internal dispute resolution: The transformation of civil rights in the workplace. Law and Society Review, 27(3): 497-534.

Edelman, L. B. 1990. Legal environments and organizational governance: The expansion of due process in the workplace. American Journal of Sociology, 95: 1401-1440.

Edwards, H. T. 1986. Alternative dispute resolution: Panacea or anathema? Harvard Law Review, 668-684.

Eigen, Z. J., \& Litwin, A. S. 2014. Justice or just between us? Empirical evidence of the tradeoff between procedural and interactional justice in workplace dispute resolution. Industrial \& Labor Relations Review, 67(1): 171-201.

Eisenberg, T., \& Hill, E. 2003. Employment arbitration and litigation: An empirical comparison. Public Law and Legal Theory Research Paper Series (New York University), 1-25.

Estreicher, S. 2001. Saturns for rickshaws: The stakes in the debate over predispute employment arbitration agreements. Ohio State Journal on Dispute Resolution, 16(3): 559-570.

Ewing, W. D. 1989. Justice on the Job: Resolving Grievances in the Nonunion Workplace. Boston, MA: Harvard Business School Press.

Farh, J. L., Lee, C., \& Farh, C. I. C. (2010). Task conflict and team creativity: A question of how much and when. Journal of Applied Psychology, 95(6), 1173-1180.

Fiss, O. M. 1983. Against settlement. Yale Law Journal, 93: 1073-1093.

Freeman, R., \& Medoff, J. L. 1984. The exit-voice trade off. In R. Freeman \& J. L. Medoff (Eds.), What do unions do? 94-110. Basic Books.

Foulkes, F. "How Top Nonunion Companies Manage Employees." Harvard Business Review, Vol. September-October, pp. 90-96.

Fox, A. 1974. Beyond Contract: Work, Power and Trust Relations. London: Faber Press. 
Gordard, J. 2014. Labor-management conflict: Where it comes from, why it varies, and what it means for conflict management systems. In W. K. Roche, P. Teague, \& A. J. S. Colvin (Eds.), The Oxford Handbook of Conflict Management in Organizations: 30-52. Oxford University Press.

Godard, J. and Delaney, J. T. 2000. "Reflections on the “High Performance” Paradigm’s implications for Industrial Relations as a Field." Industrial and Labor Relations Review, Vol. 53, No. 3, pp. 482-502.

Ichniowski, C. 1986. The effects of grievance activity on productivity. Industrial \& Labor Relations Review, 40(1): 75-89.

Jehn, K. A. 1995. A multi-method examination of the benefits and detriments of intragroup conflict, Administrative Science Quarterly, 40(2): 256-282.

Jehn, K. A., \& Bendersky, C. 2003. Intragroup conflict in organizations: A contingency perspective on the conflict-outcome relationship. Research in Organizational Behavior, 25: 187-242.

Jehn, K. A., \& Mannix, E. A. 2001. The dynamic nature of conflict: A longitudinal study of intragroup conflict and group performance. Academy of Management Journal, 44(2): 238-251.

Jehn, K. A., Northcraft, G. B., and Neale, M. A. (1999). Why differences make a difference: A field study of diversity, conflict and performance in workgroups. Administrative Science Quarterly, 44(4), 741-763.

Katz, H. C., Kochan, T. A., \& Weber, M. R. 1985. Assessing the effects of industrial relations systems and efforts to improve the quality of working life on organizational effectiveness. Academy of Management Journal, 28(3): 509-526.

Katz, C. H. , Kochan, T., and Gobeille, K. October 1983. "Industrial Relations Performance, Economic Performance, and QWL Programs: An Interplant Analysis." Industrial and Labor Relations Review, Vol. 37, No. 1, pp. 3-17.

Kochan, Thomas A., Robert B. McKersie, and Peter Cappelli. 1984. Strategic choice and industrial relations theory. Industrial Relations, 23(1): 16-39.

Kochan, Thomas A., Harry C. Katz, and Robert B. McKersie. 1986. The transformation of American industrial relations. Ithaca, NY: Cornell University Press.

Lewin, D. 2001. IR and HR perspectives on workplace conflict: What can each learn from the other?. Human Resource Management Review, 11(4): 453-485.

Lewin, D., \& Peterson, R. B. 1988. The grievance procedure in practice and research: Review and assessment. In D. Lewin \& R. B. Peterson (Eds.), The modern grievance procedure in the United States: 21-60. Greenwood Press. 
Lipsky, R. Seeber, \& R. D. Fincher. (2003). Emerging systems for managing workplace conflict: 29-74. San Francisco: Jossey-Bass.

Lipsky, David B., and Ariel C. Avgar. 2008. Toward a strategic theory of workplace conflict management. Ohio State Journal on Dispute Resolution, 24(1): 143-90.

Lipsky, David B., Ariel C. Avgar, J. Ryan Lamare, and A. Gupta. 2014. Conflict resolution in the United States. In William K. Roche, Paul Teague, and Alexander J.S. Colvin (Eds.). The Oxford Handbook of Conflict Management in Organizations. Oxford, UK: Oxford University Press, 405-424.

Rahim, M. A., \& Magner, N. R. (1995). Confirmatory factor analysis of the styles of handling interpersonal conflict: First-order factor model and its invariance across groups. Journal of Applied Psychology, 80(1), 122.

Rahim, M.A. (2002). Toward a theory of managing organizational conflict. International Journal of Conflict Management, 13(3), 206-235.

Rees, D. I. 1991. Grievance procedure strength and teacher quits. Industrial \& Labor Relations Review, 45(1): 31-43.

Roche, W., \& Teague, P. 2012. Do conflict management systems matter? Human Resource Management, 51(2): 231-258.

Roche, W. K., Teague, P. and Colvin, A J.S.. 2014. Introduction: Developments in conflict management. In W. K. Roche, P. Teague, \& A. J. S. Colvin (Eds.), The Oxford Handbook of Conflict Management in Organizations: 30-52. Oxford University Press.

Shaw, J. D., Zhu, J., Duffy, M. K., Scott, K. L., Shih, H. A., \& Susanto, E. 2011. A contingency model of conflict and team effectiveness. Journal of Applied Psychology, 96(2): 391-400.

Stone, Katherine V.W. 1996. Mandatory arbitration of individual employment rights: The yellow dog contract of the 1990s. Denver University Law Review 73(4):1017-1050.

Sutton, J. R., Dobbin, F., Meyer, J. W., \& Scott, W. R. 1994. The legalization of the workplace. American Journal of Sociology, 4, 944-971.

Thomas, K. W. 1976. Conflict and Conflict Management. In M. D. Dunnette (Ed.), Handbook of Industrial and Organizational Psychology: 889-935, Chicago: Rand-McNally.

Ury, W. L., Brett, J. M. and Gloldberg, S. B. 1988. Getting Disputes Resolved: Designing Systems to Cut the Cost of Conflict. San Francisco: Jossey-Bass.

Wall, J. A., \& Callister, R. R. 1995. Conflict and its management. Journal of Management, 21(3): 515-558. 
Walton, E. R. and McKersie, B. R. 1965. A Behavioral Theory of Labor Negotiations: An Analysis of a Social Interaction System. New York, NY: McGraw-Hill Book Company.

Westin, F. A. and Feliu, G. A. 1988. Resolving Employment Disputes without Litigation. Washington, D.C.: The Bureau of National Affairs Inc. 